\title{
Learning in Cnidaria: A systematic review
}

\author{
Ken Cheng ${ }^{1}$
}

Accepted: 19 November 2020 / Published online: 13 January 2021

(C) The Psychonomic Society, Inc. 2021

\begin{abstract}
Using the database Web of Science, a systematic search for literature on learning in Cnidaria, both non-associative and associative, was conducted. Cnidaria comprise hydras, box jellies, (true) jellyfish, corals, and sea anemones, a group of animals possessing diffuse networks of nerves known as nerve nets or neural nets. Being neighbors on the animal evolutionary tree to bilaterian animals, the vast collection of (mostly) bilaterally symmetric animals with brains ranging from tiny worms to giant whales, the cognitive capacities of Cnidaria inform the evolution of nervous systems and cognition in bilateria. I failed to find literature on learning in corals and box jellies. Habituation has been amply shown in hydras, jellyfish, and sea anemones, while sensitization has been studied in detail in sea anemones, including some neurobiological details in the release of nematocysts or poisoned darts for capturing prey. One well-controlled study found evidence for classical conditioning with shock in sea anemones, in addition to two other lesser-controlled demonstrations. The relevance of associative learning in sea anemones, embodied cognition, and representationsal issues when it comes to animals without central brains is discussed.
\end{abstract}

Keywords Hydra $\cdot$ Jellyfish $\cdot$ Sea anemones $\cdot$ Habituation $\cdot$ Sensitization $\cdot$ Classical conditioning

\section{Introduction}

Of all the animals in the world, four phyla are considered basal (Holland, 2011); the rest fall under a huge umbrella labeled bilateria. Bilateria are characterized by bilateral (mirror) symmetry, possess concentrations of neurons called brains, and range from tiny rotifers to giant whales. The basal phyla include two groups with no nervous systems and no muscles, Porifera (sponges) and Placozoa, best known by the species Trichoplax adhaerens (Schierwater \& Eitel, 2015). Trichoplax sucks up nutrient particles via its epithlelium, a process akin to exuding stomach juices on food called transepithelial cytophagy (Schierwater \& Eitel, 2015). Sponges filter seawater for food and possess elements that form nervous systems in bilateria, including sensors, ion channels, and, in some groups, even electrical conduction (Leys, 2015). The other two basal phyla, Ctenophora (comb jellies, not to be confused with jellyfish) and Cnidaria (jellyfish, box jellies, hydras, corals, sea anemones), do possess muscles and nervous systems but their nervous systems differ from those of bilateria (Holland, 2011; Moroz, 2015; Satterlie, 2018;

Ken Cheng

ken.cheng@mq.edu.au

1 Department of Biological Sciences, Macquarie University, Sydney, NSW 2109, Australia
Watanabe, 2017). Both these phyla contain diffuse nervous networks called nerve nets or neural nets without a central brain. Basal phyla are understudied in biology (Dunn, Leys, \& Haddock, 2015); thus, the aim of this review was to examine learning in basal phyla that possess neural nets. Given that no literature was found on learning in Ctenophora, the focus of this review shifted to concentrate on learning in Cnidaria, a topic that, to my knowledge, has never been reviewed.

Four classes make up Cnidarians (Holland, 2011; Santhanam, 2020; see Fig. 1). Anthozoans comprise sea anemones and corals, largely sessile animals, with corals usually forming large colonies harboring what can be called an ecosystem, such as the Great Barrier Reef. Hydrozoans consist mostly of small-sized hydra, although the giant colonial Portuguese Man o'War also falls in this class. Many hydras filter water to extract food particles such as fish eggs or hunt down tiny animals with stinging tentacles (Santhanam, 2020). Scyphozoans are considered true jellyfish, while the fourth class, cubozoans, comprises box jellies (Holland, 2011). Both these latter classes possess soft, bell-shaped bodies, more cuboid in shape in cubozoans. Both classes hunt prey actively with their stinging tentacles (Santhanam, 2020).

Two layers make up the body plan of Cnidaria, an ectoderm on the outside and an endoderm on the inside (Holland, 2011). Sandwiched in between is a fluid mass of proteins with perhaps some scattered cells called mesoglea. Cnidaria do not possess bilateral symmetry but most show rotational 

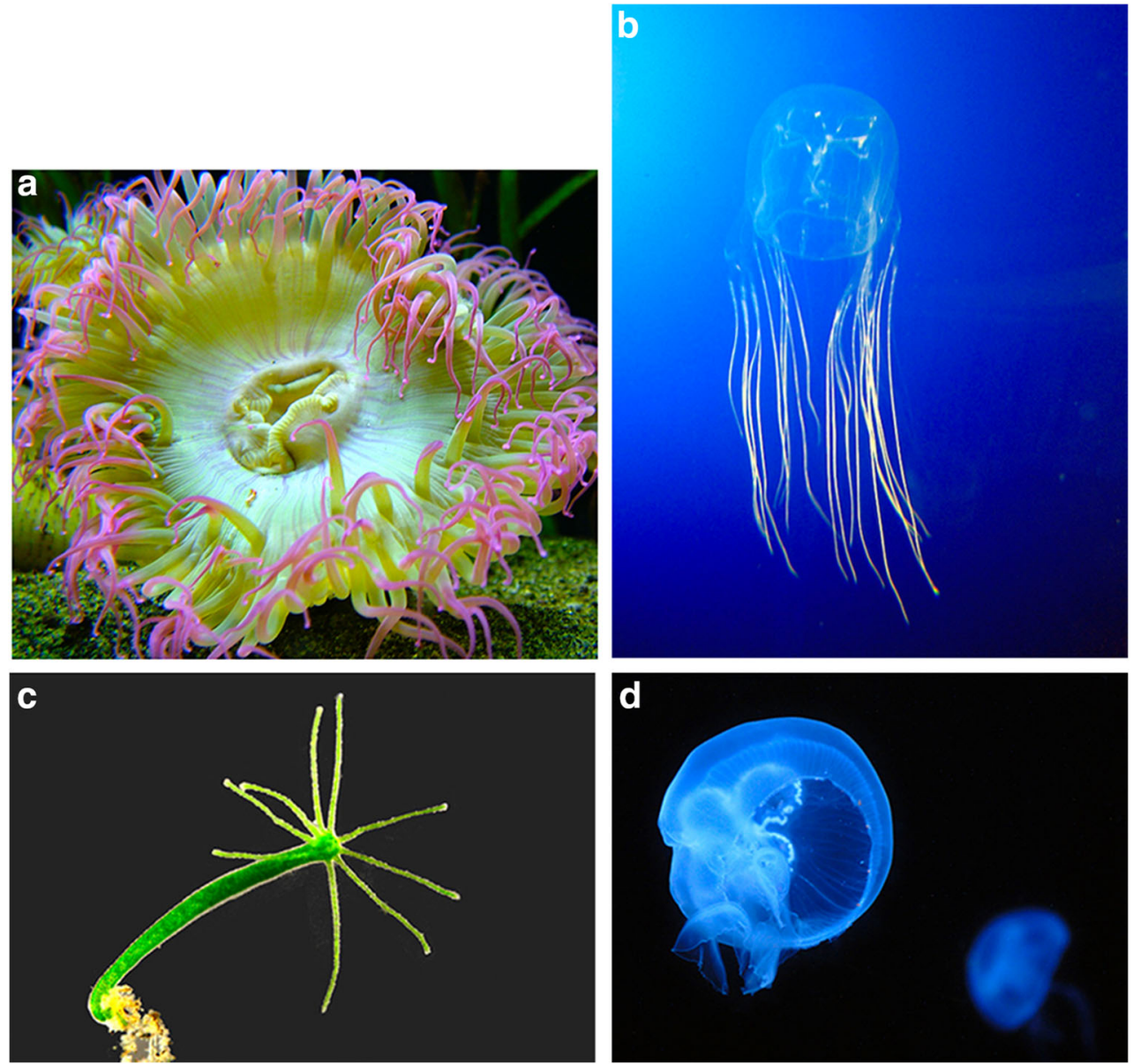

Fig. 1 Cnidarian animals. (a) The sea anemone Anthopleura elegantissima. (b) A sea wasp, Chironex sp. (c) The green hydra Hydra viridissima. (d) The jellyfish Aurelia aurita. In color online. Sources: (a) https://commons.wikimedia.org/wiki/File:Anthopleura_elegantissima, Seattle.jpg Author: David Davies. Licence: https://creativecommons.org/ licenses/by-sa/2.0/deed.en (b) https://commons.wikimedia.org/wiki/File: Avispa_marina_cropped.png Author: Guido Gautsch, modified by

symmetry, so that if one rotates the animal along one axis, the body plan maps onto itself at regular intervals of rotation. These neural-netted denizens of water possess one opening serving as both mouth and anus, called the oral disk. In the mouth-up orientation, the Cnidarian is known as a polyp, while in the mouth-down orientation, it is called a medusa. Whether sessile, as with many sea anemone polyps, or mobile, as with jellyfish and box jelly medusas, Cnidarians hunt their food, using what unites the group and gives them their name, cnidocytes (Fig. 2). Cnidocytes are stinging cells that fire nasty darts for attack and defence, with Holland (2011, p. 31) calling them "tiny barbed harpoons ... laced with poison."

The firing of cnidocytes features in a key and substantial part of the literature on non-associative learning, in particular, in sensitization in sea anemones. Functionally, the firing is regulated because cnidocytes are expensive, their cost arising not only from their complex structure but from the fact that they are single-use darts (Anderson \& Bouchard, 2009).
Mithril. Licence: https://creativecommons.org/licenses/by-sa/2.0/deed. en (c) https://commons.wikimedia.org/wiki/File:Mikrofoto.de-Hydra 15.jpg Author: Frank Fox. Licence: https://creativecommons.org/ licenses/by-sa/3.0/de/deed.en (d) https://commons.wikimedia.org/wiki/ File:Aurelia_aurita_(aka).jpg Author: André Karwath. Licence: https:// creativecommons.org/licenses/by-sa/2.5/deed.en

Working like a disposable harpoon gun, each time a cnidocyte fires, the entire cell needs to be replaced - thus, not only the harpoon but the entire gun. A complex cast of supporting cells including cilia and chemoreceptors sense stimuli to regulate cnidocyte firing (Anderson \& Bouchard, 2009; Ozacmak, Thorington, Fletcher, \& Hessinger, 2001; see Fig. 3). When a cnidocyte discharges, the spring-loaded dart shoots out at great speed, taking $\sim 3 \mathrm{~ms}$ to fire (Holstein \& Tardent, 1984). At its fast phase, travel speed reaches $2 \mathrm{~m} / \mathrm{s}$, with an astonishing acceleration of $40,000 \mathrm{~g}$.

Deciding - if that is the correct word - when to fire cnidocytes to capture food is one aspect of Cnidarian lifestyle for which it would be useful to be able to learn. Other aspects of food acquisition could favor the evolution of learning as well. Sea anemones live in communities with symbiotic fishes such as clown fish (subfamily Amphiprioninae). Clown fish sometimes bring food to sea anemones. Life in the sea also features nasty events, from predators to harmful chemicals to 


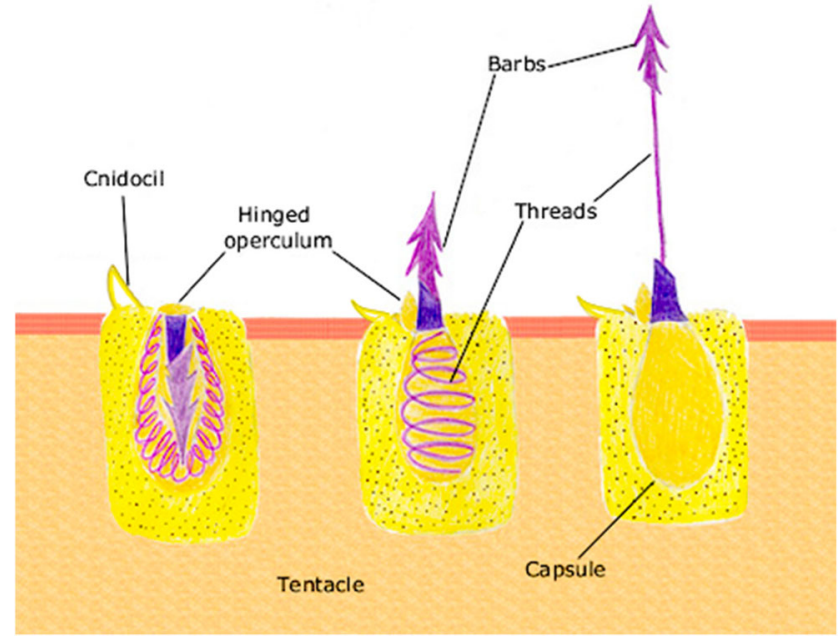

Fig. 2 Nematocyst discharge from a cnidocyte. Illustration of the discharge of a Cnidarian nematocyst. A spring-loaded dart sits inside the cnidocyte cell (left). When a lid (operculum) is opened (middle), the poisoned barbs shoot out at great speed (right). In color online. Source: https://commons.wikimedia.org/wiki/File:Nematocyst_ discharge.png Author: Spaully. Public domain

competing conspecific animals. Learning about those events and stimuli could benefit Cnidarians.

Neurobiologically, Cnidarian nervous systems and behavior inform the study of bilaterians with their evolved brains because Cnidaria form the closest group to bilaterians in the animal evolutionary tree. Debate continues on whether Porifera (Feuda et al., 2017; Simion et al., 2017) or Ctenophora (Whelan et al., 2017) constitutes the sister group in animals, that is, the most basal group from which all other animals first branched. The verdict on this uncertain aspect of deep evolutionary history depends on the dataset entered into

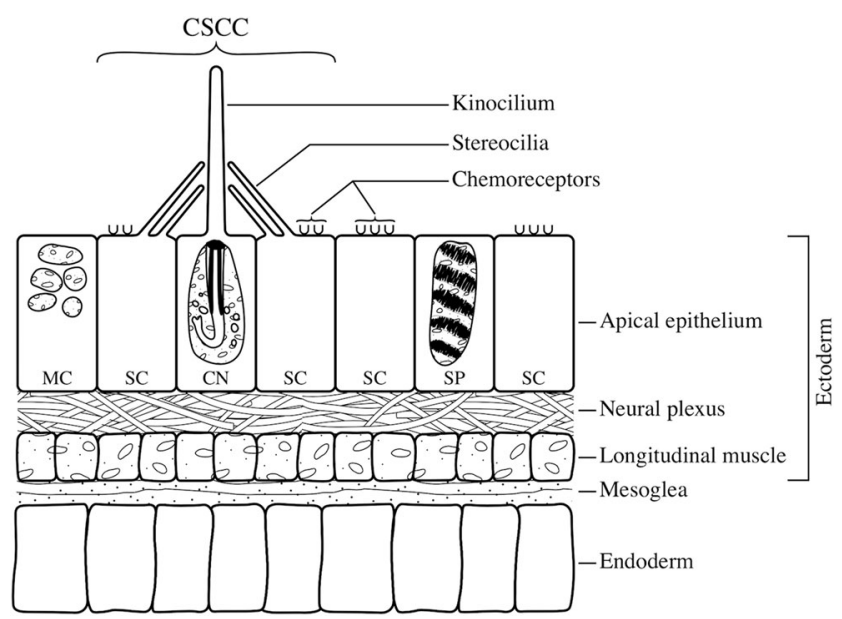

Fig. 3 A supporting cast for the cnidocyte known as a cnidocyte/ supporting cell complex (CSCC). Mechanoreceptors (stereocilia) and chemoreceptors sense information to regulate cnidocyte firing. $M C$ mucus-secreting cell, $S C$ supporting cell, $C N$ nematocyst-containing nematocyte, $S P$ sprirocyst-containing spirocyte. From Ozacmak et al. (2001). Reprinted with permission from the publisher, The Company of Biologists analysis and the method of calculating trees. All these analyses agree, however, in putting Cnidaria next to bilateria as evolutionary neighbors. Looking at the neurobiology and capacities of Cnidaria promises insights into the origins of learning, cognition, and neurobiology in bilaterians (Koizumi, 2007; Koizumi et al., 2015; Satterlie, 2011; Watanabe, 2017).

While bluntly characterized as a neural net, the nervous systems of Cnidaria exhibit more organization and centralization than a totally decentralized diffuse network of nerves. Concentrations of neurons called nerve rings show some centralization (Satterlie, 2011), near the tentacles in hydrozoans (Koizumi, 2007; Koizumi et al., 2015), near the margins of the umbrella in jellyfish and box jellies (scyphozoans and cubozoans; Satterlie, 2011). These rings coordinate the diffuse network of nerves, the latter seen as conduits to muscles (Satterlie, 2011). Koizumi (2007) considers such rings as precursors to the bilaterian brain; Satterlie (2011) describes them as "neuronal condensation into ganglion-like structures" (abstract, p. 1215); and one scientist likens such centralized structures in jellyfish to having a brain (Albert, 2011).

What such brainless animals with some centralized rings of neurons can learn is of interest in elucidating the origins of learning and cognition (Perry, Barron, \& Cheng, 2013), especially in bilaterians. In this regard, it is just as important to delineate limitations (or what a group does not show by way of learning and cognition) as well as capabilities for locating the evolutionary origins of any form of learning, cognition, or indeed of any trait in general. A broad sweep across the animal kingdom of both positives and negatives is required for the comparative method for locating the origins of traits (Perry et al., 2013).

Learning in Cnidaria connects with a current topic in the philosophy of mind, that of embodied cognition. One current concept defines embodied cognition as cognitive activities orchestrated largely outside of the central brain (Cheng, 2018; Hochner, 2012; see also Keijzer, 2017). Lacking a central brain, all learning in Cnidaria constitutes embodied cognition by this definition. This form of embodied cognition raises questions about how information necessary for accomplishing tasks is represented at the cognitive and neurobiological levels.

With a comparative outlook in mind, I set out to review literature on learning in Cnidaria encompassing both nonassociative learning and associative learning. The textbook distinction stipulates that in associative learning the learner connects or links two different kinds of events (Bouton, 2007). In classical conditioning, for example, the learner is said to learn a link between different types of events in its world. Non-associative learning takes place with the repetition of the same kind of event or else some unrelated event changes the reaction of an organism to some type of stimulus event. A non-exhaustive but systematic and comprehensive search of the literature targeted all the major groups of Cnidaria, 
searching by their common names. As will be revealed, I did not find anything on corals or box jellies but can describe learning studies on hydra, jellyfish, and especially sea anemones. An overview of the methods of literature search is followed by sections on different types of learning: habituation, sensitization, and associative learning. The review ends with a discussion of the importance of associative learning in these brainless animals, what learning in Cnidaria implies for embodied cognition, and representational issues in learning without a central brain.

\section{Methods}

I searched the database Web of Science using key terms, picked out relevant publications based on their titles, and then followed relevant references in the works that I read. The searches were conducted in March and April of 2019 and checked once more in May and June of 2020. To canvas the taxa, I used the topic terms anemone, coral, hydra, box jell*, and jellyfish. These terms were crossed with terms of learning: habituation, sensitiz* (and its other variant in spelling, sensitis*), and conditioning, using the Boolean logical term AND in Web of Science. Thus, 15 separate searches were conducted, five animal groups by three phenomena of learning. I did not find any relevant learning literature for box jellies. I also did not find any relevant literature for coral AND habituation, and coral AND sensitization. I found close to 10,000 cases for coral AND conditioning and filtered this list by using the term learning in the refine options in Web of Science. This filtering led to no relevant publications on learning in corals. As a result, this review reports work on anemones, hydra, and jellyfish.

This method may not be exhaustive, in that not all literature that reported learning phenomena might have labeled the phenomena as learning, with its current terms of habituation, sensitization, and classical and operant conditioning. Nevertheless, the search methods provided a comprehensive publication list on three taxa, and following reference trails to earlier work led to finding literature in which phenomena of sensitization were labelled as "facilitation." Thus, I have located some of the key historical background to the modern study of learning in Cnidaria.

\section{Review}

\section{Habituation}

Habituation is the decrease in responding to a stimulus type that is repeatedly presented (Bouton, 2007). The stimulus is typically something considered neutral and innocuous. If one plays a pure tone to a typical vertebrate laboratory animal such as a rat, it exhibits an orienting response, lifting its head and moving it, as if searching for the sound source. Over repeated presentations, the response diminishes. The performance of a waning of a response may, however, be driven by different underlying processes, such as fatigue, so that further criteria are needed to show that non-associative learning underlies the performance. To establish an interpretation of habituation, the phenomenon of dishabituation needs to be shown as well. In dishabituation, a new type of stimulus leads to the response in question once more. In the rat example, a different kind of sound, such as a click, should once more induce the orienting response. Further nuances and distinctions may be given (Thompson \& Spencer, 1966), but for the purposes of this review, we could consider dishabituation as a key phenomenon for supporting an interpretation of habituation to a stimulus type.

Studies suggesting habituation in sea anemones date back to the turn of the twentieth century. Jennings (1905) fed two different species of the Aiptasia genus pieces of food repeatedly. One delicacy consisted of filter paper soaked in the juice of crab meat. Not surprisingly, after repeated proferrings, the anemones rejected the filter paper (Table 1). Jennings interpreted the rejection as satiation, but modern studies on vertebrate animals suggest that habituation also plays a role in eating behaviors, or rather, its cessation (McSweeney, Hinson, \& Cannon, 1996; McSweeney \& Murphy, 2009). In some trial sequences, a sea anemone that rejected filter paper would still accept crab meat, akin to a phenomenon of dishabituation.

More convincing evidence of habituation came from Jennings' mentee Allabach (1905), who carried out this line of work on the sea anemone Metridium marginatum. A number of Allabach's (1905) findings cast doubt on the hypothesis that satiation is the only explanation for sea anemones' rejection of proffered food. When the sea anemone rejected food proffered to one side of the animal, Allabach found that food proffered to the other side would still be accepted. As already mentioned, after a sea anemone rejected filter paper from multiple presentations, it would often still accept crab meat. Casting doubt on satiation as an explanation for the rejection of filter paper, eating a few bits of crab meat would sometimes lead to the acceptance of proffered filter paper again. Filter paper presented repeatedly but not swallowed was also eventually rejected. Swallowing was prevented by using tweezers to snatch the food out of the sea anemone's oesophagus. Repeated presentation of crab meat while preventing swallowing also led to rejection of filter paper. These last findings are consistent with habituation as an interpretation but are also consistent with associative learning as an interpretation. Conceivably, the sea anemones could have learned to avoid taking in experimentally proffered food because it led to aversive consequences of having tweezers shoved into their oesophagus. This interpretation, however, remains 
Table 1 Summary of evidence on learning in Cnidaria reported in the review

\begin{tabular}{|c|c|c|c|}
\hline Learning type & Animal group & Evidence & Brief description of evidence \\
\hline Habituation & $\begin{array}{l}\text { Hydras } \\
\text { Jellyfish } \\
\text { Sea anemones }\end{array}$ & $\begin{array}{l}\text { Yes } \\
\text { Yes } \\
\text { Yes }\end{array}$ & $\begin{array}{l}\text { Reduced reaction to repeated mechanical stimulation } \\
\text { Reduced reaction to repeated mechanical stimulation } \\
\text { Reduced reaction to repeated presentation of food } \\
\text { Reduced reaction to repeated mechanical stimulation } \\
\text { Reduced aggression over repeated encounters with another conspecific animal }\end{array}$ \\
\hline Sensitization & $\begin{array}{l}\text { Hydras } \\
\text { Jellyfish } \\
\text { Sea anemones }\end{array}$ & $\begin{array}{l}\text { Hint of evidence } \\
\text { No studies found } \\
\text { Yes }\end{array}$ & $\begin{array}{l}\text { Multiple electrical or mechanical stimulus events needed to elicit muscle contraction } \\
\text { Chemicals could sensitize muscle contraction in response to mechanical stimulation } \\
\text { Touching with a starfish, a predator, could sensitize response to electrical stimulation } \\
\text { Repeated touches with the tentacles of a heterospecific species could lead to increased attack } \\
\text { responses } \\
\text { Repeated presentation of a conspecific animal could lead to increased attack responses } \\
\text { Stimulation with several 3-s long jet streams of water led to increased responding (closing of } \\
\text { oral disk) to a short stream of water } \\
\text { Various chemical and mechanical stimuli could sensitize the release of stinging cnidocytes used } \\
\text { in prey capture }\end{array}$ \\
\hline \multirow[t]{2}{*}{$\begin{array}{l}\text { Classical } \\
\text { conditioning }\end{array}$} & $\begin{array}{l}\text { Hydras } \\
\text { Jellyfish }\end{array}$ & $\begin{array}{l}\text { No studies found } \\
\text { No studies found }\end{array}$ & $\begin{array}{l}\overline{ } \\
\end{array}$ \\
\hline & Sea anemones & Yes & $\begin{array}{l}\text { Electrical stimulation paired with food led to mouth opening with electrical stimulation alone in } \\
\text { a study lacking a full suite of control conditions } \\
\text { Light followed by shock led to responding (closing of oral disk) to light alone in a study with a } \\
\text { full suite of control conditions } \\
\text { Seawater applied to the oral disk followed by food led to opening of the oral disk to seawater } \\
\text { alone }\end{array}$ \\
\hline \multirow[t]{2}{*}{$\begin{array}{l}\text { Operant } \\
\text { conditioning }\end{array}$} & $\begin{array}{l}\text { Hydras } \\
\text { Jellyfish }\end{array}$ & $\begin{array}{l}\text { No studies found } \\
\text { No studies found }\end{array}$ & - \\
\hline & Sea anemones & Hint of evidence & Conch presentation followed by shock led some sea anemones to avoid conch \\
\hline
\end{tabular}

Box jellies and corals are not in the table because no relevant evidence on any form of learning was found for these taxa

unsubstantiated, as we do not know how aversive the tweezers were to the animals.

As a final finding, Allabach (1905) reported that repeated streams of water squirted from a pipette would lead to a diminution of responding as well. The response was the contraction of an expanded disk. Allabach did not report any tests of dishabituation, so that an interpretation of habituation is less certain in this case. Allabach's studies provide fascinating data, but we bemoan the lack of tabulated details of results, as the paper is lacking entirely in data figures or tables.

In the same year, Wagner (1905) found reactions in hydra suggestive of habituation. The species was likely Hydra viridis, but the passage did not make clear which species was being tested. With repeated mechanical stimulation, the initial contraction exhibited by hydras diminished. The contraction did not diminish if the interval between stimuli was long. Wagner did not, however, test dishabituation in any way.
Some half a century later, Rushforth and co-workers tested hydras (Hydra pirardi) on habituation (Rushforth, Burnett, \& Maynard, 1963; Rushforth, Krohn, \& Brown, 1964). Replicating Wagner's pattern of results, repeated mechanical stimulation led to decreasing contraction as a response (Rushforth et al., 1963). Switching to a light stimulus led to increased contracting once again, while repeated presentation of light once again led to diminished contracting, both signatures of habituation. Rushforth et al. (1964) found that the contraction response to mechanical stimuli can be inhibited. It is inhibited when the hydra is feeding. Biochemically, the team found that gluthathione, in its reduced state, mediated the inhibition. Adding gluthathione to the water surrounding a hydra is sufficient to inhibit the contraction response.

Logan (1975) found solid evidence for habituation in the sea anemone Anthopleura elegantissima. Jet streams of water fired from a device were used to induce contractions in the sea anemones. Repeated streams led to lower levels of 
responding. A different tactile stimulus led to dishabituation; that is, the animals contracted to a new type of stimulus. A long interstimulus interval also led to spontaneous recovery of the contracting response, at least in two of three animals tested.

Using the same species and jet streams of water again, long-term habituation could also be found in Anthopleura elegantissima (Logan \& Beck, 1978). After one training session of 35 to 80 trials, retention of contracting, defined as exhibiting at least $80 \%$ of the maximum contraction, was found after $72 \mathrm{~h}$ (Fig. 4). In some cases, sensitization within a session was found (Logan \& Beck, 1977), a theme that I return to in reviewing sensitization.

A different kind of behavior that at times reveals habituation and at times sensitization is aggression, by way of various acrorhagial responses. As already mentioned, Cnidarian animals possess various poison-filled stinging weapons; these are called acrorhagi as a group. A clone of sea anemones fights other clones in territorial disputes (Ayre \& Grosberg, 1995; Knowlton, 1996). Various behaviors scored as aggression include the expansion of acrorhagi and release of stinging cells such as nematocysts. A sizeable and detailed literature documents processes of sensitization in sea anemones' aggressive responses, but some studies also suggest habituation. Basically, a sea anemone might get used to a familiar neighbor and reduce aggressive behaviors toward this neighbor.

One study measured changes in the threshold for aggressive responses (Brace, Pavey, \& Quicke, 1979). The threshold was the number of touches with an amputated tentacle required to elicit an aggressive response. Changes in thresholds across trials were interpreted in terms of habituation and sensitization. When I took the numbers in Brace et al.'s (1979) Table II and ran a paired t-test between the threshold values of the first and second presentations, however, I did not find a significant difference. The evidence is thus dubious.
Good evidence for habituating to new neighbors was found in a laboratory study on Metridium senile (Purcell \& Kitting, 1982). Aggression in the form of acrorhagial responses would decrease over days when strangers were placed together. Aggression increased again when a new stranger was introduced, showing the phenomenon of dishabituation.

In the field, the sea anemone Anthopleura elegantissima discriminated between familiar and unfamiliar neighbors that were transplanted to their vicinity (Sebens, 1984). The test animals behaved aggressively toward unfamiliar neighbors, displaying full acrorhagial responses, but not toward familiar neighbors. Sebens suggested habituation as the interpretation. Some demonstration of dishabituation would have strengthened the interpretation.

Similar to M. senile, the sea anemone Actinia equina also showed both habituation and dishabituation in aggression to conspecifics (Brace \& Santer, 1991). Over repeated experimental pairings with the same conspecific, aggressive responses decreased. Exposure to a new conspecific, on the other hand, led to increased aggression again. Habituation lasted at least a medium term because $4 \mathrm{~h}$ after the dishabituating trial, exposure to the original partner resulted again in low levels of aggression. Another presentation of the original partner $48 \mathrm{~h}$ later, however, led to increased aggression once again. Nevertheless, a form of savings in learning was found, in that another presentation of the original partner $4 \mathrm{~h}$ later showed low aggression again. These patterns of habituation and dishabituation were only found in the color morphs that showed substantial levels of aggression. One morph hardly displayed any aggression, so that it hit a floor effect: aggression could not drop much from the initial and continuing low levels.

Examining and experimenting on Anemonia viridis in the field, Williams (1992) found that the sea anemones sometimes detached their pedal disk with the presentation of another sea

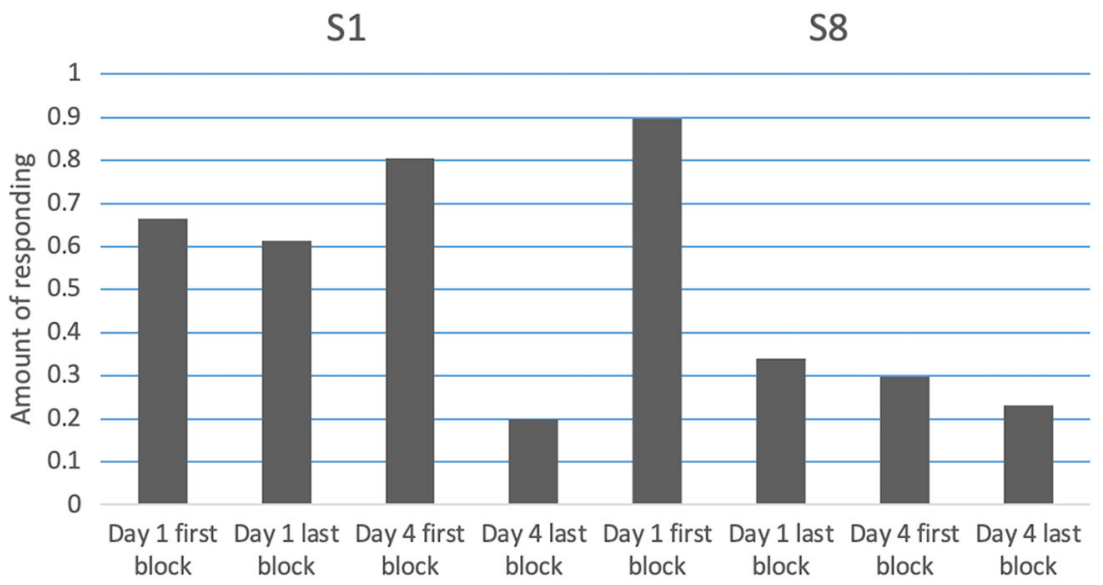

Fig. 4 The retention of habituation over 3 days in one sea anemone, Anthopleura elegantissima. The $y$-axis had been transformed so that the 3 days. Animal S1 showed some sensitization followed by some habituation on Day 1. On Day 4, habituation set in faster than in Day 1. Data estimated from Figs. 1 and 2 of Logan and Beck (1978) and redrawn consisted of five trials. Animal S8 showed retention of habituation over 
anemone. Low levels of aggression were interpreted as habituation, but this study lacked the clean design of repeated presentations followed by the presentation of some dishabituating stimulus.

Testing A. elegantissima in repeated encounters, one study found both habituation and sensitization in aggressive responses (Ayre \& Grosberg, 1995). Full acrorhagial attacks were scored; the authors criticized other studies for scoring other less full-blown forms of aggression exhibited by the sea anemones. It took 5 days of pairing different clones together, but on the fifth day, habituation was found in one clone. Some indications of dishabituation or at least stimulus-specific habituation were found in that those exposed to a different partner clone from the one that they encountered on the previous 4 days did not show habituation.

On the other hand, based on staged fights in the laboratories, the same authors argued against habituation in A. elegantissima (Ayre \& Grosberg, 1996). Each polyp was only tested once, but polyps from neighboring colonies in the field fought abundantly. This interpretation of a lack of habituation is not warranted without further testing. The laboratory is a different environment from the native habitat of the sea anemones, and the animals were tested within $28 \mathrm{~h}$ of being collected. Habituation is known to be context-sensitive in several taxa (e.g., nematodes: Rankin, 2000). It is conceivable that Ayre and Grossberg found context-sensitive habituation in sea anemones. This is one topic that deserves further study to ascertain or refute.

Finally, one study found habituation in a jellyfish, Aurelia aurita (Johnson \& Wuensch, 1994). Streams of water, a shake of the container holding the test animal, or a gentle touch were used as tactile stimuli. Repetitions at short intervals of one kind of stimulus led to decreased responding, although it was unclear what the authors considered as responding. An interstimulus interval of 2 min led to decreased responding; an interstimulus interval of 6 min did not. Dishabituation was shown because using a different kind of mechanical stimulus led to the responses again.

\section{Sensitization}

Sensitization is a process in which responding to some stimulus increases as a function of either repeated stimuli of the same kind or the presentation of some unrelated stimulus. In textbook cases, strong and biologically significant events are often foisted on laboratory animals to induce sensitization, with electric shock being a convenient manipulation (Bouton, 2007; Carew, 2000). In Cnidaria, all published cases of sensitization showcase sea anemones, with repeated stimulation being one route to obtaining or increasing a response. The phenomenon has also been called facilitation (Pantin, 1935a, b, c, d).
As with habituation, signs of sensitization in sea anemones were already found by the turn of the twentieth century (Table 1). Allabach (1905) found that a sea anemone (M. marginatum) that refused filter paper soaked in crab meat juice might be induced to take filter paper again after being fed some pieces of crab meat, a kind of priming phenomenon. The only hint of sensitization in hydra stemmed from this period (Wagner, 1905). Repeated mechanical stimulation might induce a hydra to move away from the region of stimulation, a behavior called "escape" (quotation marks in the original; Wagner, 1905).

Thirty years later, a series of papers documented sensitization in sea anemones (Calliactis parasitica), with the phenomenon called facilitation (Pantin, 1935a, b, c, d). The work led to a plethora of biological and chemical details on the process over the course of the last century. In the basic phenomenon, a single electrical stimulus would not elicit a response of muscle contraction from the sea anemone, no matter what its strength. But multiple stimuli would. Pantin inferred from stimulating the disk what was called "interneural facilitation" via diffuse nervous conduction across the nerve net of the sea anemone. Successive stimuli would elicit more and more responding, suggesting the recruitment of other neurons than the one being stimulated: other nerves were sensitized (Pantin, 1935a). The stimuli had to be spaced close enough in time to produce this increasing staircase of responding (Pantin, 1935c). This graded responding from interneural facilitation (sensitization) gave "a superficial appearance of purposiveness" (Pantin, 1935b, p. 153).

Facilitation or sensitization was also found in the sea anemone $M$. senile, in which a similar pattern of increased responding with repeated stimulation was found (Hall \& Pantin, 1937). Once again, the increase in responding depended on stimulus frequency and not stimulus strength. Temperature affected the effects of the interstimulus interval, shown much more clearly in M. senile than in C. parasitica. As a rule, the shorter the interval between two successive stimuli, the bigger was the response to the second interval, up to a point. At a short enough interstimulus interval, a plateau (as Hall \& Pantin called it) or saturation point was reached; further shortening the interstimulus interval did not increase responding any more. Many biological processes slow down at lower temperatures, and the interstimulus interval at which the saturation point is reached is longer at lower temperatures. Thus, in lower compared with higher temperatures, the maximum responding is reached at a longer interstimulus interval.

In the ensuing years and decades, the mechanisms underlying sensitization/facilitation in sea anemones were dissected in Pantin's laboratory and by others. Magnesium and carbon dioxide block the sensitization/facilitation, while calcium, potassium, and hydrogen ions increase the sensitized response in Calliactis and Metridium (Ross \& Pantin, 1940). These 
authors also distinguished conceptually a muscular excitation process from a sensitization process at the neuromuscular junction that makes the muscular excitation effective. As I have been implying, sensitization does not trigger muscular contractions, but enables other forms of stimulation to trigger action in muscles.

The effects of chemicals on sensitization in sea anemones continued in Ross's lab (Ross, 1945a, b). The test animals, C. parasitica, were subjected to a range of chemicals added to the water in which they were immersed (Ross, 1945a). Most of these drugs and chemicals did not have immediate actions; it typically took $1-2 \mathrm{~h}$ for any effects to be observed. At even longer durations, the chemicals generally had a depressant effect. A number of drugs had no notable effect other than this long-duration depressant effect, including acetylcholine, curare, adrenaline, and epinine. Nevertheless, some chemicals that act like acetylcholine had facilitating effects, increasing the extent of sensitization: tyramine, tryptamine, and a drug called 933F (the chemical piperoxan hydrochloride), and in the second study (Ross, 1945b), ground-up extracts of sea anemones Metridium or Calliactis. After being immersed in these chemicals, sometimes, but not always, a single stimulus is enough to trigger muscle contractions, making the chemicals act like sensitizing agents. But the chemicals as a group failed to exhibit the full suite of properties expected of a sensitizing agent: enhancing responding, triggering the response with a single stimulus, and delayed decay of sensitization.

Sensitization, also called facilitation, was found in another sea anemone, Stomphia coccinea, in response to electric shock (Wilson, 1959). Repeated shocks led to increased swimming responses. With seven subthreshold shocks, the sensitization could last for hours or days. At one stimulus every $3 \mathrm{~s}$, no sensitization was found. At eight stimuli per second, swimming responses appeared after $\sim 8 \mathrm{~s}$ of stimulation. Although the first shock led to no responding, the second shock led to some responding by way of retraction and closure. Touching the sea anemone with a starfish (Dermasterias genus) could also lead to sensitization: a number of subthreshold electrical stimuli could lead to responding. This training regime (touching with starfish followed by electrical stimulation) could also lead to responding to the starfish alone, a phenomenon that could be interpreted as classical conditioning, with the starfish serving as the conditioned stimulus. Wilson, however, rejected this interpretation in favor of sensitization as the interpretation. This is sensible given the lack of controls needed to demonstrate classical conditioning. The entire paper (Wilson, 1959) contained descriptions but no numerical data, figures, or tables, making it difficult to interpret the patterns of data.

Sensitization of acrorhagial expansion as a response was suggested by another study (Bigger, 1980). What changed was the threshold for eliciting a response, defined as the number of touches with an excised tentacle, at a rate of one per second, that was required for the response to appear. As a rule, the threshold decreased over successive trials to touches with tentacles of two heterospecific species. A drop in threshold from trial 1 to trial 2 was evident across a range of intertrial intervals up to $120 \mathrm{~min}$. But on the third and fourth trials, some increases in threshold were seen at some intertrial intervals. A lack of statistical analyses did not help readers to make out the patterns of data.

Sensitization of acrorhagial expansion lasting up to 5 days was found in another study, on Anemonia sulcata (Sauer, Müller, \& Weber, 1986). With repeated pairings between the same pair of animals, acrorhagial expansion took place with less latency across trials. The authors wrote of an "inducible 'alloimmune memory' " (their quotation marks), an altered reaction to some chemical that lasts for days.

In a study already reviewed in the section on habituation, sensitization of full attacks was found in a study on A. elegantissima (Ayre \& Grosberg, 1995). Repeated pairings of the same pair of animals often led to increases in full attacks. Paralleling Sauer et al.'s (1986) results, the introduction of new partners gave evidence that the memory was specific to one individual (likely, individual from one clone).

A mix of habituation and sensitization was also found in A. elegantissima with moderately intense water jets as stimuli (Logan \& Beck, 1977). At first, repeated bouts of 0.3-s water streams spaced $60 \mathrm{~s}$ apart led to habituation, evidenced by less closing of the oral disk. Then four longer streams of water, lasting $3 \mathrm{~s}$ each, were blasted at the animals. Responding varied across five individuals tested, but in some, this regime led eventually to sustained sensitization (closing of oral disk) in further sessions with the short, 0.3 -s water jets.

From the 1980s onwards, research on the biochemical and neurobiological basis of acrorhagial sensitization increased, with David Hessinger's lab contributing many studies. The lab had developed a technique of measuring the adhesive force between a tentacle and a test object as a dependent measure for the extent of acrorhagial responding (Giebel, Thorington, Lim, \& Hessinger, 1988; Thorington \& Hessinger, 1988). The team focused on the number of microbasic p-mastigophores, one type of stinging cnidocyte, discharged by the sea anemone: the more mastigophores discharged, the more the adhesive force. Testing Aiptasia pallida, Thorington and Hessinger (1988) identified two classes of chemicals that act as sensitizers, amino and imino acid and histamine as one class, and $\mathrm{N}$-acetylated sugars as another class. Chemoreception of chemicals from prey sensitize the cnidae of sea anemones, such that they discharge upon mechanical contact with the prey. Thus, glycine and nacetylneuraminic acid (NANA) increased the number of mastigophores discharged, acting as chemical sensitizers (Giebel et al., 1988). The test probe acted as the tactile trigger, while the chemicals served to sensitize. The increase was dose-dependent. While a moderate concentration of the 
chemical increased discharge, too high a concentration led to a lower level of discharge, making an inverted U-shaped dosedependence function. Using the method of counting discharged mastigophores, Watson and Hessinger (1989b) found that mucin-gold, free mucin, as well as NANA acted as sensitizers for Halliplanella luciae.

Movement of prey near a sea anemone will send vibrations through water to the predator. Not surprisingly, vibrations also act as sensitizers. Tactile contact after vibrational stimuli triggers cnidocytes to release nematocysts. Cnidocytes are tuned to particular vibrational frequencies, meaning that they discharge more upon tactile contact at selected frequencies, ranging from $30 \mathrm{~Hz}$ to $75 \mathrm{~Hz}$ in seawater for H. luciae (Watson \& Hessinger, 1989a). Chemosensitizers such as $\mathrm{N}$-acetylated sugars (Watson \& Hessinger, 1989b) or dibytyril cyclic adenosine monophospate (AMP; Watson \& Hessinger, 1992) modified the most sensitive range to lower frequencies of 5 $40 \mathrm{~Hz}$. These frequencies are characteristics of struggling prey. Adenylate cyclase in the membrane of supporting cells is implicated in the sensitization because activating adenylate cyclase chemically produces the aforementioned effects (Watson \& Hessinger, 1992). The sensitization lasts for at least $90 \mathrm{~s}$, and a short burst of vibrations of less than $1 \mathrm{~s}$ is sufficient (Watson, Venable, \& Mire, 2000). The sensitization shows a rhythmic pattern, with the rhythm depending on the vibrational frequency (Watson et al., 2000). The process of sensitization coordinates the reliance on chemical and tactile cues in the predatory attacks of sea anemones.

Calcium ions also play a role in sensitization in sea anemones. Inhibitors of L-type calcium channels block the sensitization by $\mathrm{N}$-acetylated sugars, but not the sensitization by proline, another sensitizer, in H. luciae (Russell \& Watson, 1995). Other chemicals that block calcium pathways can also reduce sensitization. On the other hand, inhibitors of calcium channels in intracellular storage sites block sensitization by proline, but not sensitization by $\mathrm{N}$-acetylated sugars. Inhibiting the uptake of $\mathrm{Ca} 2+$ into vesicles sensitizes nematocyst discharge. Dose dependence was again important in these effects, with the inverted U-shaped function shown in a good number of graphs displaying sensitization as a function of concentration of chemicals. Russell and Watson concluded that $\mathrm{N}$-acetylated sugars and proline stimulate two different calcium pathways to sensitization.

Another study suggested a role for cyclic AMP in the sensitization of nematocysts (Ozacmak et al., 2001). Testing A. pallida, Ozacmak et al. found that n-acetylneuraminic acid (NANA), which has already been shown to be a sensitizing chemical, led to higher levels of cyclic AMP in the ectoderm of tentacles in a dose-dependent manner. The pattern of dosedependence parallels the pattern found in sensitization by NANA, suggesting a role for cyclic AMP in sensitization.

More recent work on sea anemones (Actinia equina) than any reviewed so far has found individual differences in fighting ability, sometimes called resource-holding potential (Lane \& Briffa, 2017, 2018a, 2018b; Rudin \& Briffa, 2012). These stable individual differences or personality differences are correlated with differences in the duration of the sea anemones' startle response to a squirt of water into the oral disk (Rudin \& Briffa, 2012), interact with extrinsic factors such as oxygen level (Lane \& Briffa, 2018b), and influence how the sea anemones fight with one another (Lane \& Briffa, 2017, 2018a, 2018b; Rudin \& Briffa, 2012). Individual differences have not featured in studies on learning in sea anemones and form an important topic for future research.

All in all, the evidence for sensitization of aggressive responses, both in capturing prey and in fighting conspecific animals, is abundant. An array of mechanical and chemical stimuli serve as sensitizers. In prey capture, it appears that the integration of multiple cues in different modalities orchestrates the attack, ensuring that the attack is on a prey rather than on other non-edible objects in the water. A diverse set of chemoreceptors and mechanoreceptors feed their information to the nerve net and on to the muscles to coordinate this important task.

\section{Conditioning}

Compared with the wealth of literature on non-associative learning in Cnidaria, the literature on conditioning, a form of associative learning, is paltry (Table 1). In associative learning, an animal links different types of events; typically, one type of event predicts another type. A textbook distinction is between classical (or Pavlovian) conditioning and operant conditioning as forms of basic associative learning. In classical conditioning, different types of events external to the animal are linked. A usually neutral stimulus, the conditioned stimulus (CS), predicts some biologically significant event, the unconditioned stimulus (UCS). In operant conditioning, an animal links its own behavior to some biologically significant outcome. These two types of conditioning are often mixed together, unavoidably. Suppose that an animal learns to do $\mathrm{X}$ under conditions $\mathrm{Y}$ to obtain some positive outcome $\mathrm{Z}$; this is a classic case of the contingency of reinforcement (reward) called positive reinforcement. When the task has been learned, $\mathrm{Y}$ becomes a reliable predictor of $\mathrm{Z}$, triggering classical conditioning. I discuss the few cases of classical and operant conditioning in Cnidaria, all on sea anemones, together.

Serious attempts at finding classical conditioning in sea anemones were first reported in 1965 (Ross, 1965). The paper mostly documented the difficulties and problems with different methods of examining classical conditioning in sea anemones. The most promising case came from experiments on $M$. senile, examining its reflex of mouth opening in response to a drop of squid extract placed on its oral disk. In conditioning trials, electrical stimulation to the base (the CS) was given 
simultaneously with the presentation of squid extract. On some later tests, the CS was given alone. On some CS-alone trials, mouth opening was found, as shown in a series of photographs.

To establish classical conditioning as the interpretation of these results, various controls are required. The accepted best control is to present both the CS and the UCS to the animal in an unpredictable manner. This control conditioning procedure, the randomized control, tests for the effects of the CS by itself or the UCS by itself, irrespective of their predictive relationship to one another. Some form of sensitization, for example, would still produce the unconditioned response under the randomized control. Ross (1965) reported as control tests a CS-only condition, which did not induce oral disk opening. The lack of full controls and full reporting makes this result preliminary rather than definitive.

The best study on classical conditioning in sea anemones, Cribina xanthogrammica, came from J. V. Haralson, Groff, and Haralson (1975). The team used shock as the UCS and the presentation of light as the CS. Shock induced folding of the oral disk as well as electrical output from the sea anemones; both these behaviors were measured. In the conditioning procedure, $15 \mathrm{~s}$ of CS was followed immediately by $5 \mathrm{~s}$ of UCS at the offset of the CS. The intertrial interval varied, with a mean of $30 \mathrm{~s}$. Conditioning led to increases in both behaviors in response to the CS, light (Fig. 5). A full suite of controls was implemented, including conditions presenting the CS (light) alone, presenting the UCS (shock) alone, and CS and UCS presented at random times rather than paired in a predictive fashion. None of these control conditions resulted in an increase in the unconditioned responses. A check of a citedreferences search on Web of Science showed that this elegant study has not been replicated to date, on the same or another species of sea anemone.

Another later study reported various phenomena suggesting classical conditioning in a different species of sea anemones, Condylactis gigantea, although none of the experiments were rigorously controlled (Hodgson, 1981). One series of experiments punished the sea anemones for the natural behavior of eating food, a paradigm of positive punishment in operant conditioning. Conch was presented to the sea anemones followed by mild shock. The animals learned to hold the food for less and less time and eventually avoided the conch altogether. When an extinction procedure was instituted, with the conch no longer followed by shock, the sea anemones took a long time before they accepted the food again, indicative of passive avoidance learning. Some stimulus specificity was found in other series of experimentation. While avoiding conch after the punishment procedure, the sea anemones would still accept fish meat as a food.

A second study by Hodgson (1981) used food as the reinforcer (UCS), and some $45^{\circ} \mathrm{C}$ seawater applied to the oral disk as the CS. After repeated pairings of seawater on the oral disk
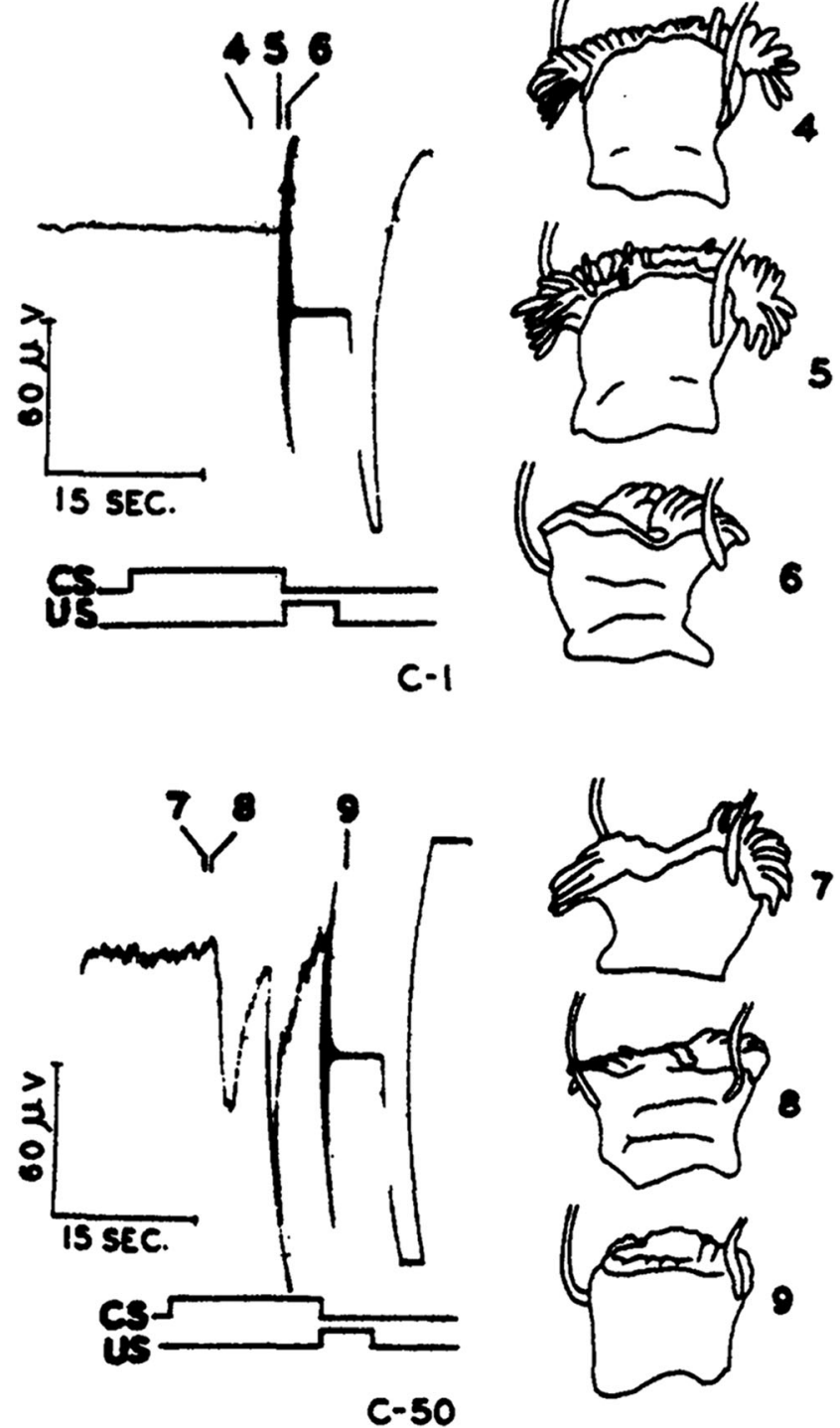

Fig. 5 Classical conditioning in the sea anemone Cribrina xanthogrammica. Drawings of one animal at different points during conditioning, on the first trial $(\mathrm{C}-1$, top) and on the 50th trial $(\mathrm{C}-50$, bottom). The points in time are indicated by the numbers on the left. CS conditioned stimulus (light), US unconditioned stimulus (shock). On trial 1 (top) the response began after the onset of the US (after 6), while on trial 50 (bottom) the response began during the CS, before the onset of the US (after 8). Accompanying physiological measurements were also obtained with an electrode. From Fig. 1 of J. V. Haralson et al. (1975). Reprinted with permission of the publisher, Elsevier

with food presentation, Hodgson reported that 162 of 420 trials showed some mouth-opening response to seawater. At one trial per day, a frequency of $31 \%$ conditioned response was observed, while with five trials per day, that frequency was $61 \%$. A CS-alone condition was reported, as well as a UCS (food)-alone condition. When seawater was given alone, or when seawater was given after food-alone training, little mouth opening was found, or else the mouth showed some closing. Notably, however, no explicitly unpaired condition was reported. 
The food conditioning might operate in the natural lives of sea anemones with their symbiont fishes providing the CS. In lab conditions, Hodgson (1981) introduced some symbiont fishes, such as the sebae clownfish Amphiprion sebae, to the sea anemones. The fish took readily to storing food in the sea anemones, some of which they retrieved at a later time. Within 3 weeks, the sea anemones would open their mouths slightly when the fish, but not the food the fish were storing, touched their tentacles while swimming. These intriguing observations are far from fully convincing demonstrations of conditioning not only because relevant control conditions were missing, but also because no tables or graphs of the data were presented.

Hodgson's (1981) study provided a fascinating range of conditioning phenomena in $C$. gigantea. The demonstration with both aversive shock and appetitive food shows some generality in conditioning. None of the experiments were rigorously controlled, so that replication of the work, whether exact or conceptual replications, is in order.

\section{Discussion}

This literature review found a dearth on learning in corals and box jellies, but plenty on hydra, jellyfish, and especially sea anemones. Of the basic learning phenomena, non-associative learning, comprising habituation and sensitization, is exhibited by hydra, jellyfish, and sea anemones. Sensitization, often called facilitation, has been well studied in sea anemones, unraveling a body of neurobiological mechanisms. Two topics have received scarce attention and require much more research examining them in more detail: non-associative learning over a longer period of time and associative learning.

In bilateria, short-term and long-term habituation (Carew, 2000; Thompson \& Spencer, 1966) as well as short-term and long-term sensitization (Carew, 2000) have been distinguished. In an animal with a small nervous system, the crab Chasmagnathus granulatus, short- and long-term habituation show not only different time courses of learning but also differences in context sensitivity (Tomsic et al., 2009), with longterm habiutation diminishing with a change of context. In the sea slug Aplysia spp., different cellular mechanisms underlie short- and long-term habituation and short- and long-term sensitization (Carew, 2000). This distinction between shortand long-term forms of learning also illustrates the theoretical importance of distinguishing learning from performance. In both short- and long-term habituation, for example, we see diminished responding immediately after some training, yet short- and long-term habituation are thought to have different underlying learning and neurobiological mechanisms.

Literature on associative learning in Cnidaria is also sparse and so far only found in sea anemones. Nevertheless, I identified three different studies reporting classical conditioning in sea anemones, one well-controlled study (J. V. Haralson et al.,
1975) and two with less than the full set of desired control conditions (Hodgson, 1981; Ross, 1965).

What does it mean to find this corpus of learning in Cnidaria, animals with perhaps incipient centralized components in their nervous systems but without brains (Koizumi, 2007; Koizumi et al., 2015; Mackie, 2004; Satterlie, 2011)? I discuss: (1) the issue of associative learning in Cnidaria and what that might imply, (2) cognition without a central brain and the relation of that feat to concepts of what constitutes cognition, and (3) representational issues of learning without a brain.

Just three studies reported on classical conditioning in sea anemones and none in any other taxa of Cnidaria, leaving the evidence base thin. This sparseness has left some authors doubtful of the existence of associative learning in Cnidaria (Bronfman, Ginsburg, \& Jablonka, 2016; Ginsburg \& Jablonka, 2010). Ginsburg and Jablonka (2010) suggested that associative learning is at most minimal in Cnidaria, while Bronfman et al. (2016) bemoaned a lack of replication of the J. V. Haralson et al. (1975) study, suggesting that unpublished negative results sit on shelves. Ginsburg and colleagues tie other agendas up with the advent of unlimited associative learning, linking its appearance to the Cambrian explosion (Ginsburg \& Jablonka, 2010) and to minimal consciousness (Bronfman et al., 2016). The term "unlimited" does not refer to association of all conceivable stimuli, something that animals with brains do not exhibit, as shown by what are called constraints on learning, a major theme since the second half of the twentieth century (Breland \& Breland, 1961; Garcia \& Koelling, 1966; Shettleworth, 1975; see Shettleworth, 2010). The sense of "unlimited" concerns stimuli in the natural lives of animals (as opposed to experimentally contrived situations) that they might be called upon to associate. To probe how unlimited associative learning is in Cnidaria, we could benefit from more studies on classical conditioning, including exact and conceptual replications of J. V. Haralson et al.'s (1975) study. Food conditioning (Hodgson, 1981; Ross, 1965), in studies lacking full control, and shock conditioning (J. V. Haralson et al., 1975), with a full suite of controls, is a start but does not satisfy the criterion of unlimitedness. From the standpoint of establishing existence, however, the evidence is clearly positive at the moment and the ball is in the court of skeptics. Were Haralson et al.'s suite of manipulations to produce positive results in any other organisms (e.g., the first study in tardigrades, Zhou et al., 2019), learning scientists would not doubt the demonstration of classical conditioning. Given the importance of the issue of associative learning for understanding the evolution of learning, more studies, with positive or negative results, must be done and be published (Perry et al., 2013).

Learning in Cnidaria means cognition without central brains, and as cognition outside of the central brain defines one interpretation of embodied cognition (Cheng, 2018; 
Hochner, 2012; see also Keijzer, 2017; Lyon, 2019; SmithFerguson \& Beekman, 2019), Cnidaria - jellyfish, hyrda, and sea anemones in particular - exhibit embodied cognition. Cnidaria join a host of organisms without brains, in some cases without nervous systems, as well as brained animals in showing cognition outside of or without a central brain.

Among animals with brains, the octopus, an invertebrate with a large nervous system (Hochner, 2012), provides a wellunderstood case of embodied cognition. Much of the control of arm movements, for example in ferrying food snatched in a sucker to the mouth, is orchestrated in the arms (Flash \& Hochner, 2005; for reviews, see: Cheng, 2018; Hochner, 2012). Even humans possess a modicum of embodied cognition in this sense, that is, of cognitive processing in the periphery (Lavoie et al., 2018). Peripheral neurons in the fingertips process information on edge orientation.

Cognition broadly defined is found in many organisms, even those without nervous systems (Godfrey-Smith, 2016; Lyon, 2019), in the latter cases clearly embodied cognition in the sense of cognition outside of a central brain. In this broad sense, cognition is defined by any kind of information processing in defence of a self bounded by a membrane, thus including single-celled organisms (Godfrey-Smith, 2016). More comprehensively formulated, Lyon (2019), adapting from Shettleworth's (2010) definition of cognition in animals, put it this way:

"Cognition is comprised of sensory and other information-processing mechanisms an organism has for becoming familiar with, valuing, and interacting productively with features of its environment in order to meet existential needs, the most basic of which are survival/persistence, growth/thriving, and reproduction." (p. 10)

Thus, plants show non-associative learning (habituation in Mimosa pudica: Gagliano, Renton, Depczynski, \& Mancuso, 2014). Plants also possess sensing mechanisms for environmental stresses that capitalize on calcium ion channels $(\mathrm{Wu}$ et al., 2020). The single-celled slime mold, Physarum polycephalum, exhibits habituation (Boisseau, Vogel, \& Dussutour, 2016), although so far not associative learning (Smith-Ferguson \& Beekman, 2019). Slime molds even display some peculiarities of decision making shown in humans (Smith-Ferguson \& Beekman, 2019). In choices between multiple options, adding a third, undesired option could change the proportion of choices of the other two more attractive options, compared with choosing between just the two more attractive options, a pattern that has been called economically irrational.

Learning in Cnidaria also raises questions about mechanisms, as does learning in plants and single-celled organisms. Neural circuits in regions of the central brain cannot be proposed for brainless Cnidaria, the kinds of circuits that have been proposed for the hippocampal formation of mammals (Rowland, Roudi, Moser, \& Moser, 2016; Sanders, RennóCosta, Idiart, \& Lisman, 2015) or the central complex of insects (Cohn, Morantte, \& Ruta, 2015; Heinze, Narendra, \& Cheung, 2018). If not circuits such as attractor networks and neural pattern-separating mechanisms, what then could underlie learning in Cnidaria? Would some of the neurobiological processes underlying well-studied animal learning systems such as the sea slug Aplysia (Carew, 2000) apply?

No firm answers to this question are at hand; this is an area that deserves further research. Probing not only the extent of learning but also the neurobiological mechanisms of learning is crucial for piecing together the evolution of learning in organisms. Other than circuits, one other proposal, speculative currently, is that stable molecules might form the basis of memory for whatever is learned (Langille \& Gallistel, 2020). In an adversarial collaboration, Langille and Gallistel presented both the proposal of neural circuits as the basis of memory (Langille) and the notion that molecules such as DNA and RNA might form a chemical basis for memory (Gallistel). If common molecules in life such as RNA could form the basis of memory, then memory might be widespread, and arise in more than the animal kingdom. In fact, even single-celled organisms could be endowed with memory capacities.

My review also reveals limitations in the literature on Cnidarian learning. The research has been sparse since the early 2000s. While mechanisms of sensitization in sea anemones have been well investigated, other phenomena of learning, including habituation and classical conditioning, have not been elucidated at all. Given how crucial classical conditioning in sea anemones is for understanding the capacities and limitations of Cnidaria, work on this topic is sorely needed, both in new experiments as well as in conceptual and exact replications of the sparse work to date. Another form of association that deserves study is the question of context specificity in habituation, something found in animals with brains (Rankin, 2000). Context specificity would mean that even the non-associative habituation has a flavor of association.

\section{Conclusions}

This review shows that Cnidaria do learn. Non-associative learning, both habituation and sensitization, has been shown in numerous studies throughout the twentieth century into this century. Evidence on associative learning is sparse and more research is needed. It is important to document limits (negative results) as well as positive results in learning in Cnidaria and indeed in other rarely studied taxa of animals. Much is known about the neurobiology of Ctenophores or comb jellies (Moroz, 2015; Tamm, 2014), but nothing is known of their learning. Among bilateria, a phylum without central brains, 
Echinoderms, is worth reviewing, as associative learning in starfish has been reported (e.g., Ormond, Hanscomb, \& Beach, 1976). It is only by documenting both the achievements and the limitations of all phyla that we can hope to understand the evolution of learning in animals (Perry et al., 2013)

Acknowledgements I would like to thank Andrew Barron and two anonymous reviewers for comments on earlier drafts of this article. The article contains no reports of original research, so that regulations regarding animal ethics do not apply. I declare no conflict of interest. None of the data or materials for the experiments reviewed here are available, and none of the experiments were preregistered. No new original data are reported.

\section{References}

Albert, D. J. (2011). What's on the mind of a jellyfish? A review of behavioural observations on Aurelia sp. jellyfish. Neuroscience \& Biobehavioral Reviews, 35, 474-482.

Allabach, L. F. (1905). Some points regarding the behavior of Metridium. The Biological Bulletin, 10, 35-43.

Anderson, P. A. V., \& Bouchard, C. (2009). The regulation of cnidocyte discharge. Toxicon, 54, 1046-1053.

Ayre, D. J., \& Grosberg, R. K. (1995). Aggression, habituation, and clonal coexistence in the sea anemone Anthopleura elegantissima. American Naturalist, 146, 427-453.

Ayre, D. J., \& Grosberg, R. K. (1996). Effects of social organization on inter-clonal dominance relationships in the sea anemone Anthopleura elegantissima. Animal Behaviour, 51, 1233-1245.

Bigger, C. H. (1980). Interspecific and intraspecific acrorhagial aggressive behavior among sea anemones: a recognition of self and notself. The Biological Bulletin, 159, 117-134.

Boisseau, R. P., Vogel, D., \& Dussutour, A. (2016). Habituation in nonneural organisms: evidence from slime moulds. Proceedings of the Royal Society B: Biological Sciences, 283, 20160446.

Bouton, M. E. (2007). Learning and behavior: A contemporary synthesis. Sunderland, MA: Sinauer Associates.

Brace, R. C., Pavey, J., \& Quicke, D. L. J. (1979). Intraspecific aggression in the colour morphs of the anemone Actinia equina: the "convention' governing dominance ranking. Animal Behaviour, 27, 553561.

Brace, R. C., \& Santer, S. J. (1991). Experimental habituation in the seaanemone Actinia equina. Hydrobiologia, 216, 533-537.

Breland, K., \& Breland, M. (1961). The misbehavior of organisms. American Psychologist, 16, 681-684.

Bronfman, Z. Z., Ginsburg, S., \& Jablonka, E. (2016). The transition to minimal consciousness through the evolution of associative learning. Frontiers in Psychology, 7, 1954.

Carew, T. J. (2000). Behavioral neurobiology: The cellular organization of natural behavior. Sunderland, MA: Sinauer Associates.

Cheng, K. (2018). Cognition beyond representation: Varieties of situated cognition in animals. Comparative Cognition \& Behavior Reviews, 13, 1-20.

Cohn, R., Morantte, I., \& Ruta, V. (2015). Coordinated and compartmentalized neuromodulation shapes sensory processing in Drosophila. Cell, 163, 1742-1755.

Dunn, C. W., Leys, S. P., \& Haddock, S. H. D. (2015). The hidden biology of sponges and ctenophores. Trends in Ecology \& Evolution, 30, 282-291.

Feuda, R., Dohrmann, M., Pett, W., Philippe, H., Rota-Stabelli, O., Lartillot, N., ... Pisani, D. (2017). Improved modeling of compositional heterogeneity supports sponges as sister to all other animals. Current Biology, 27, 3864-3870. e3864.

Flash, T., \& Hochner, B. (2005). Motor primitives in vertebrates and invertebrates. Current Opinion in Neurobiology, 15, 660-666.

Gagliano, M., Renton, M., Depczynski, M., \& Mancuso, S. (2014). Experience teaches plants to learn faster and forget slower in environments where it matters. Oecologia, 175, 63-72.

Garcia, J., \& Koelling. (1966). The relation of cue to consequence in avoidance learning. Psychonomic Science, 4, 123-124.

Giebel, G. E. M., Thorington, G. U., Lim, R. Y., \& Hessinger, D. A. (1988). Control of cnida discharge: II. Microbasic p-mastigophore nematocysts are regulated by 2 classes of chemoreceptors. Biological Bulletin, 175, 132-136.

Ginsburg, S., \& Jablonka, E. (2010). The evolution of associative learning: A factor in the Cambrian explosion. Journal of Theoretical Biology, 266, 11-20.

Godfrey-Smith, P. (2016). Individuality, subjectivity, and minimal cognition. Biology \& Philosophy, 31, 775-796.

Hall, D. M., \& Pantin, C. F. A. (1937). The nerve net of the Actinozoa: V. Temperature and facilitation in Metridium senile. Journal of Experimental Biology, 14, 71-78.

Haralson, J. V., Groff, C. I., \& Haralson, S. J. (1975). Classical conditioning in the sea anemone Cribrina xanthogrammica. Physiology and Behavior, 15, 455-460.

Heinze, S., Narendra, A., \& Cheung, A. (2018). Principles of insect path integration. Current Biology, 28, R1043-R1058.

Hochner, B. (2012). An embodied view of octopus neurobiology. Current Biology, 22, R887-R892.

Hodgson, V. S. (1981). Conditioning as a factor in the symbiotic feeding relationship of sea anemones and anemone fishes. Proceedings of the International Coral Reef Symposium, 553-561.

Holland, P. (2011). The animal kingdom: A very short introduction. Oxford: Oxford University Press.

Holstein, T., \& Tardent, P. (1984). An ultrahigh-speed analysis of exocytosis: nematocyst discharge. Science, 223, 830-833.

Jennings, H. S. (1905). Modifiability in behavior. I. Behavior of sea anemones. Journal of Experimental Zoology, 2, 447-472.

Johnson, M. C., \& Wuensch, K. L. (1994). An investigation of habituation in the jellyfish Aurelia aurita. Behavioral and Neural Biology, 61, 54-59.

Keijzer, F. A. (2017). Evolutionary convergence and biologically embodied cognition. Interface Focus, 7, 20160123.

Knowlton, N. (1996). Trench warfare on the shore: interclonal aggression in sea anemone. Trends in Ecology \& Evolution, 11, 271-272.

Koizumi, O. (2007). Nerve ring of the hypostome in hydra: Is it an origin of the central nervous system of bilaterian animals? Brain, Behavior and Evolution, 69, 151-159.

Koizumi, O., Hamada, S., Minobe, S., Hamaguchi-Hamada, K., Kurumata-Shigeto, M., Nakamura, M., \& Namikawa, H. (2015). The nerve ring in cnidarians: its presence and structure in hydrozoan medusae. Zoology, 118, 79-88.

Lane, S. M., \& Briffa, M. (2017). The price of attack: rethinking damage costs in animal contests. Animal Behaviour, 126, 23-29.

Lane, S. M., \& Briffa, M. (2018a). How does the environment affect fighting? The interaction between extrinsic fighting ability and resource value during contests. Journal of Experimental Biology, 221, jeb187740.

Lane, S. M., \& Briffa, M. (2018b). Immune function and the decision to deploy weapons during fights in the beadlet anemone, Actinia equina. Journal of Experimental Biology, 221, jeb169201.

Langille, J. J., \& Gallistel, C. R. (2020). Locating the engram: Should we look for plastic synapses or information-storing molecules? Neurobiology of Learning and Memory, 169, 107164.

Lavoie, E. B., Bertrand, J. K., Stone, S. A., Wispinski, N. J., Sawalha, J., \& Chapman, C. S. (2018). Examining the "species" of situated 
cognition in humans. Comparative Cognition \& Behavior Reviews, $13,31-34$.

Leys, S. P. (2015). Elements of a 'nervous system' in sponges. Journal of Experimental Biology, 218, 581-591.

Logan, C. A. (1975). Topographic changes in responding during habituation to water-stream stimulation in sea anemones Anthopleura elegantissima. Journal of Comparative and Physiological Psychology, 89, 105-117.

Logan, C. A., \& Beck, H. P. (1977). Persistent sensitization following habituation in the sea-anemone Anthopleura elegantissima. Journal of Biological Psychology, 19, 22-24.

Logan, C. A., \& Beck, H. P. (1978). Long-term retention of habituation in the sea anemone Anthopleura elegantissima. Journal of Comparative and Physiological Psychology, 92, 928-936.

Lyon, P. (2019). Of what is "minimal cognition" the half-baked version? Adaptive Behavior, https://doi.org/10.1177/1059712319871360.

Mackie, G. O. (2004). Central neural circuitry in the jellyfish Aglantha. Neurosignals, 13, 5-19.

McSweeney, F. K., Hinson, J. M., \& Cannon, C. B. (1996). Sensitization-habituation may occur during operant conditioning. Psychological Bulletin, 120, 256-271.

McSweeney, F. K., \& Murphy, E. S. (2009). Sensitization and habituation regulate reinforcer effectiveness. Neurobiology of Learning and Memory, 92, 189-198.

Moroz, L. L. (2015). Convergent evolution of neural systems in ctenophores. Journal of Experimental Biology, 218, 598-611.

Ormond, R. F. G., Hanscomb, N. J., \& Beach, D. H. (1976). Food selection and learning in the crown-of-thorns starfish, Acanthaster planci (L). Marine Behaviour and Physiology, 4, 93-105.

Ozacmak, V. H., Thorington, G. U., Fletcher, W. H., \& Hessinger, D. A. (2001). N-acetylneuraminic acid (NANA) stimulates in situ cyclic AMP production in tentacles of sea anemone (Aiptasia pallida): Possible role in chemosensitization of nematocyst discharge. Journal of Experimental Biology, 204, 2011-2020.

Pantin, C. F. A. (1935a). The nerve net of the Actinozoa: I. Facilitation. Journal of Experimental Biology, 12, 119-138.

Pantin, C. F. A. (1935b). The nerve net of the Actinozoa: II. Plan of the nerve net. Journal of Experimental Biology, 12, 139-155.

Pantin, C. F. A. (1935c). The nerve net of the Actinozoa: IV. Facilitation and the "staircase". Journal of Experimental Biology, 12, 389-396.

Pantin, C. F. A. (1935d). The nerve-net of the Actinozoa: III. Polarity and after-discharge. Journal of Experimental Biology, 12, 156-164.

Perry, C. J., Barron, A. B., \& Cheng, K. (2013). Invertebrate learning and cognition: relating phenomena to neural substrate. Wiley Interdisciplinary Reviews-Cognitive Science, 4, 561-582.

Purcell, J. E., \& Kitting, C. L. (1982). Intraspecific aggression and population distributions of the sea anemone Metridium senile. The Biological Bulletin, 162, 345-359.

Rankin, C. H. (2000). Context conditioning in habituation in the nematode Caenorhabditis elegans. Behavioral Neuroscience, 114, 496505 .

Ross, D. M. (1945a). Facilitation in sea anemones: I. The action of drugs. Journal of Experimental Biology, 22, 21-31.

Ross, D. M. (1945b). Facilitation in sea anemones. II. Tests on extracts. Journal of Experimental Biology, 22, 32-36.

Ross, D. M. (1965). The behavior of sessile coelenterates in relation to some conditioning experiments. Animal Behaviour Supplement, 1, 43-55.

Ross, D. M., \& Pantin, C. F. A. (1940). Factors influencing facilitation in Actinozoa. The action of certain ions. Journal of Experimental Biology, 17, 61-73.

Rowland, D. C., Roudi, Y., Moser, M.-B., \& Moser, E. I. (2016). Ten years of grid cells. Annual Review of Neuroscience, 39, 19-40.

Rudin, F. S., \& Briffa, M. (2012). Is boldness a resource-holding potential trait? Fighting prowess and changes in startle response in the sea anemone, Actinia equina. Proceedings of the Royal Society B: Biological Sciences, 279, 1904-1910.

Rushforth, N. B., Burnett, A. L., \& Maynard, R. (1963). Behavior in hydra: Contraction responses of Hydra pirardi to mechanical and light stimuli. Science, 139, 760-761.

Rushforth, N. B., Krohn, I. T., \& Brown, L. K. (1964). Behavior in hydra: Inhibition of the contraction responses of Hydra pirardi. Science, $145,602-604$.

Russell, T. J., \& Watson, G. M. (1995). Evidence for intracellular stores of calcium ions involved in regulating nematocyst discharge. Journal of Experimental Zoology, 273, 175-185.

Sanders, H., Rennó-Costa, C., Idiart, M., \& Lisman, J. (2015). Grid cells and place cells: an integrated view of their navigational and memory function. Trends in Neurosciences, 38, 763-775.

Santhanam, R. (2020). Biology and ecology of venomous marine Cnidarians. Singapore: Springer.

Satterlie, R. (2018). Cnidaarian neurobiology. In J. H. Byrne (Ed.), The Oxford handbook of invertebrate neurobiology (pp. DOI: https:// doi.org/10.1093/oxfordhb/9780190456757.9780190456013. 9780190456757). Oxford: Oxford University Press.

Satterlie, R. A. (2011). Do jellyfish have central nervous systems? Journal of Experimental Biology, 214, 1215-1223.

Sauer, K. P., Müller, M., \& Weber, M. (1986). Alloimmune memory for glycoproteid recognition molecules in sea anemones competing for space. Marine Biology, 92, 73-79.

Schierwater, B., \& Eitel, M. (2015). Placozoa. In A. Wanninger (Ed.), Evolutionary developmental biology of invertebrates 1: Introduction, Non-Bilateria, Acoelomorpha, Xenoturbellida, Chaetognatha (pp. 108-114). Vienna: Springer-Verlag.

Sebens, K. P. (1984). Agonistic behavior in the intertidal sea-anemone Anthopleura xanthogrammica. Biological Bulletin, 166, 457-472.

Shettleworth, S. J. (1975). Reinforcement and the organization of behavior in golden hamsters: Hunger, environment and food reinforcement. Journal of Experimental Psychology: Animal Behavior Processes, 1, 56-87.

Shettleworth, S. J. (2010). Cognition, evolution, and behavior, second edition. New York: Oxford University Press.

Simion, P., Philippe, H., Baurain, D., Jager, M., Richter, D. J., Di Franco, A., ... Ereskovsky, A. (2017). A large and consistent phylogenomic dataset supports sponges as the sister group to all other animals. Current Biology, 27, 958-967.

Smith-Ferguson, J., \& Beekman, M. (2019). Who needs a brain? Slime moulds, behavioural ecology and minimal cognition. Adaptive Behavior, https://doi.org/10.1177/1059712319826537.

Tamm, S. L. (2014). Cilia and the life of ctenophores. Invertebrate Biology, 133, 1-46.

Thompson, R. F., \& Spencer, W. A. (1966). Habituation: A model phenomenon for the study of neuronal substrates of behavior. Psychological Review, 73, 16-43.

Thorington, G. U., \& Hessinger, D. A. (1988). Control of cnida discharge. 1. Evidence for 2 classes of chemoreceptor. The Biological Bulletin, 174, 163-171.

Tomsic, D., de Astrada, M. B., Sztarker, J., \& Maldonado, H. (2009). Behavioral and neuronal attributes of short-and long-term habituation in the crab Chasmagnathus. Neurobiology of Learning and Memory, 92, 176-182.

Wagner, G. (1905). Memoirs: on some movements and reactions of Hydra. Journal of Cell Science, 2, 585-622.

Watanabe, H. (2017). Back through time: How cnidarians and basal metazoans shed light on ancient nervous systems. In S. Shigeno, Y. Murukami \& T. Nomura (Eds.), Brain evolution by design (pp. 45-75). Tokyo: Springer.

Watson, G. M., \& Hessinger, D. A. (1989a). Cnidocyte mechanoreceptors are tuned to the movements of swimming prey by chemoreceptors. Science, 243, 1589-1591. 
Watson, G. M., \& Hessinger, D. A. (1989b). Cnidocytes and adjacent supporting cells form receptor-effector complexes in anemone tentacles. Tissue \& Cell, 21, 17-24.

Watson, G. M., \& Hessinger, D. A. (1992). Receptors for N-acetylated sugars may stimulate adenylate cyclase to sensitize and tune mechanorecptors involved in triggering nematocyst discharge. Experimental Cell Research, 198, 8-16.

Watson, G. M., Venable, S., \& Mire, P. (2000). Rhythmic sensitization of nematocyst discharge in response to vibrational stimuli. Journal of Experimental Zoology, 28, 262-269.

Whelan, N. V., Kocot, K. M., Moroz, T. P., Mukherjee, K., Williams, P., Paulay, G., . . . Halanych, K. M. (2017). Ctenophore relationships and their placement as the sister group to all other animals. Nature Ecology \& Evolution, 1, 1737-1746.
Williams, R. B. (1992). Pedal disk detachment of the sea anemone Anemonia viridis: A newly recognized response to tentacular contact between colour varieties. Scientia Marina, 56, 337-346.

Wilson, D. M. (1959). Long-term facilitation in a swimming sea anemone. Journal of Experimental Biology, 36, 526-532.

Wu, F., Chi, Y., Jiang, Z., Xu, Y., Xie, L., Huang, F., . . Wu, X. (2020). Hydrogen peroxide sensor HPCA1 is an LRR receptor kinase in Arabidopsis. Nature, 578, 577-581.

Zhou, S., DeFranco, J. P., Blaha, N. T., Dwivedy, P., Culver, A., Nallamala, H., . . . Dumas, T. C. (2019). Aversive conditioning in the tardigrade, Dactylobiotus dispar. Journal of Experimental Psychology: Animal Learning and Cognition, 45, 405-412.

Publisher's note Springer Nature remains neutral with regard to jurisdictional claims in published maps and institutional affiliations. 